\title{
The effect of intraoperative lidocaine infusion on opioid consumption and pain after totally extraperitoneal laparoscopic inguinal hernioplasty: a randomized controlled trial
}

\author{
Anup Ghimire ${ }^{1}$, Asish Subedi ${ }^{2^{*}}$ (D), Balkrishna Bhattarai ${ }^{2}$ and Birendra Prasad Sah²
}

\begin{abstract}
Background: As a component of multimodal analgesia, the administration of systemic lidocaine is a well-known technique. We aimed to evaluate the efficacy of lidocaine infusion on postoperative pain-related outcomes in patients undergoing totally extraperitoneal (TEP) laparoscopies inguinal hernioplasty.

Methods: In this randomized controlled double-blind study, we recruited 64 patients to receive either lidocaine 2\% (intravenous bolus $1.5 \mathrm{mg} \cdot \mathrm{kg}^{-1}$ followed by an infusion of $2 \mathrm{mg} \cdot \mathrm{kg}^{-1} \cdot \mathrm{h}^{-1}$ ), or an equal volume of normal saline. The infusion was initiated just before the induction of anesthesia and discontinued after tracheal extubation. The primary outcome of the study was postoperative morphine equivalent consumption up to $24 \mathrm{~h}$ after surgery. Secondary outcomes included postoperative pain scores, nausea/vomiting (PONV), sedation, quality of recovery (scores based on QoR-40 questionnaire), patient satisfaction, and the incidence of chronic pain.

Results: The median (IQR) cumulative postoperative morphine equivalent consumption in the first $24 \mathrm{~h}$ was $0(0-1)$ $\mathrm{mg}$ in the lidocaine group and $4[1-8] \mathrm{mg}$ in the saline group $(p<0.001)$. Postoperative pain intensity at rest and during movement at various time points in the first $24 \mathrm{~h}$ were significantly lower in the lidocaine group compared with the saline group $(p<0.05)$. Fewer patients reported PONV in the lidocaine group than in the saline group $(p<$ 0.05). Median QoR scores at $24 \mathrm{~h}$ after surgery were significantly better in the lidocaine group (194 (194-196) than saline group $184(183-186)(p<0.001)$. Patients receiving lidocaine were more satisfied with postoperative analgesia than those receiving saline $(p=0.02)$. No difference was detected in terms of postoperative sedation and chronic pain after surgery.
\end{abstract}

Conclusions: Intraoperative lidocaine infusion for laparoscopic TEP inguinal hernioplasty reduces opioid consumption, pain intensity, PONV and improves the quality of recovery and patient satisfaction.

Trial registration: ClinicalTrials.gov- NCT02601651. Date of registration: November 10, 2015.

Keywords: Inguinal hernia, Laparoscopy, Lidocaine, Opioid analgesic, Postoperative pain

\footnotetext{
* Correspondence: asishsubedi19@gmail.com; ashish.subedi@bpkihs.edu

${ }^{2}$ Department of Anesthesiology \& Critical Care Medicine, BP Koirala Institute of Health Sciences, Dharan, Nepal

Full list of author information is available at the end of the article
}

(c) The Author(s). 2020 Open Access This article is licensed under a Creative Commons Attribution 4.0 International License, which permits use, sharing, adaptation, distribution and reproduction in any medium or format, as long as you give appropriate credit to the original author(s) and the source, provide a link to the Creative Commons licence, and indicate if changes were made. The images or other third party material in this article are included in the article's Creative Commons licence, unless indicated otherwise in a credit line to the material. If material is not included in the article's Creative Commons licence and your intended use is not permitted by statutory regulation or exceeds the permitted use, you will need to obtain permission directly from the copyright holder. To view a copy of this licence, visit http://creativecommons.org/licenses/by/4.0/. The Creative Commons Public Domain Dedication waiver (http://creativecommons.org/publicdomain/zero/1.0/) applies to the data made available in this article, unless otherwise stated in a credit line to the data. 


\section{Background}

Inadequate pain relief after surgery causes undesirable effects. On the other hand, excessive use of opioids produces several adverse effects and might delay recovery $[1,2]$. Therefore, a multimodal analgesia regimen is recommended in the perioperative setting as it provides superior analgesia and reduces opioid requirement [3]. Intravenous (IV) lidocaine is a widely studied drug for multimodal analgesia. IV lidocaine at the doses between $1.5-3 \mathrm{mg} . \mathrm{kg}^{-1} \cdot \mathrm{h}^{-1}$ produces analgesic, antihyperalgesic, and anti-inflammatory effects [4]. Besides, a low dose of lidocaine is relatively safe and more feasible for perioperative use [4-7]. Additional benefits of lidocaine infusion include a reduction in the incidence of postoperative nausea and vomiting, early return of bowel motility and improved quality of recovery [8].

Several studies have shown that perioperative lidocaine infusion reduces postoperative pain intensity and opioid consumption, while others have found lidocaine to be ineffective [8]. These inconsistent findings may be due to variation in surgical procedure, dose and duration of lidocaine infused. Interestingly, a current update from Cochrane based meta-analysis found a weak evidence for IV lidocaine compared to placebo on early postoperative pain scores and overall opioid requirements [9]. On the contrary, other recently published meta-analyses have shown improvement in postoperative pain-related outcomes with lidocaine infusion during laparoscopic clolecystectomy $[10,11]$.

Although lidocaine infusion was effective for postoperative analgesia in open inguinal hernia surgery [12], its use has not been reported in totally extraperitoneal (TEP) laparoscopic inguinal hernioplasty. Therefore, the primary objective of our study was to compare the effects of intraoperative lidocaine infusion on postoperative opioid consumption following TEP laparoscopic inguinal hernioplasty.

\section{Methods}

This prospective randomized double-blind clinical trial was conducted at the BP Koirala Institute of Health Sciences (BPKIHS) from December 2015 to March 2017. Ethical approval for this study (Ref No. IRC/520/015) was provided by the Institutional review committee of BPKIHS, Dharan, Nepal (Member secretary Dr. Ashish Shrestha) on 24 June 2015. Before enrollment of patients, the trial was registered by the principal investigator (AG) at clinicaltrials.gov (Ref No. NCT02601651). The trial was conducted according to Good Clinical Practice and the Consolidated Standards of Reporting Trials (CONSORT) guidelines.

Patients were screened for eligibility (AG) during the pre-anesthetic visit at the in-patient-unit, the night before surgery. Male patients aged between 18 and 65 years, of ASA physical status I-II, planned for laparoscopic TEP repair of the inguinal hernia were eligible. Patients were excluded if they were obese, unable to comprehend the pain assessment scale, allergic to local anesthetics, on pain medication or anti-arrhythmic drugs, or had, psychiatric disorders, cardiac arrhythmia, hepatorenal disease or epilepsy.

After obtaining written informed consent, all eligible participants were randomly assigned, in a 1:1 ratio, to receive either lidocaine (intervention) or normal saline (placebo comparator) infusion. The anesthesia supporting staff created the trial-group assignment from the computer-based randomization list, which remained secured in sequentially numbered sealed opaque envelopes and concealed until after enrollment.

On the day of surgery, an anesthesia assistant not involved in the study prepared the drug solution after breaking the codes. Patients received one of the two assigned study medications just before the induction of anesthesia: Lidocaine group received an IV bolus of 1.5 mg. $\mathrm{kg}^{-1}$ lidocaine (Lox $2 \%$, Neon pharmaceuticals limited, Mumbai, India) followed by a continuous infusion of $2 \mathrm{mg}$. $\mathrm{kg}^{-1} \cdot \mathrm{h}^{-1}$ until the tracheal extubation; The saline group received an equal volume of IV $0.9 \%$ normal saline (NS) bolus followed by a continuous infusion. Patients, attending anesthesiologists, and the investigator who collected the data and assessed the outcomes were unaware of the trial-group assignment.

Patients received no premedication. During the preanesthetic visit, they were educated on the numeric pain rating scale (NRS, $0-10 \mathrm{~cm}$ ) for postoperative pain, where 0 is no pain and 10 is the worst imaginable excruciating pain. In the operating room, standard monitoring was applied. Just before the induction of anesthesia, patients received the study drug, according to the group allocation. Anesthesia was induced with IV fentanyl $1.5 \mu \mathrm{g} . \mathrm{kg}^{-1}$ and propofol $2-2.5 \mathrm{mg} . \mathrm{kg}^{-1}$ till the cessation of verbal response and the tracheal intubation was facilitated with vecuronium $0.1 \mathrm{mg} . \mathrm{kg}^{-1} \mathrm{IV}$. The lungs were mechanically ventilated in volume control mode, maintaining the end-tidal carbon dioxide $\left(\mathrm{ETCO}_{2}\right)$ between 35 and $45 \mathrm{mmHg}$.

Intravenous paracetamol $1 \mathrm{~g}$ was administered for 15 min after tracheal intubation. Pre-incisional infiltration in the three trocar sites was done with $2 \mathrm{ml}$ of $0.25 \%$ bupivacaine. Anesthesia was maintained with an air / oxygen mixture (inspired oxygen fraction 0.40) and isoflurane, adjusting the end-tidal concentration of isoflurane to maintain mean arterial pressure (MAP) within $20 \%$ of the baseline. IV fentanyl $0.5 \mu \mathrm{g} . \mathrm{kg}^{-1}$ was supplemented intraoperatively if MAP and heart rate increased by $20 \%$ from the baseline after ensuring adequate endtidal concentration of isoflurane, neuromuscular blockade and targeted range of $\mathrm{ETCO}_{2}$. The adequate 
neuromuscular blockade was achieved with supplemental doses of vecuronium IV bolus after observing curare notch in capnograph. Any episode of intraoperative hypotension (MAP $<65 \mathrm{mmHg}$ ) and bradycardia (heart rate $<50$ beats. $\mathrm{min}^{-1}$ ) was treated with ephedrine $5 \mathrm{mg}$ and atropine $0.4 \mathrm{mg}$ IV respectively.

An experienced surgeon performed the TEP laparoscopic surgery for inguinal hernia repair as described elsewhere [13]. Ketorolac $30 \mathrm{mg}$ IV was administered at the end of surgery and scheduled to be given at 8 $\mathrm{h}$ intervals. The residual neuromuscular block was reversed with IV neostigmine $0.05 \mathrm{mg}$. $\mathrm{kg}^{-1}$ and glycopyrrolate $0.01 \mathrm{mg}$. $\mathrm{kg}^{-1}$. Following successful tracheal extubation, the study drug was discontinued and the patient was transferred to the postanesthesia care unit (PACU).

The blinded investigator assessed the postoperative outcomes. The primary outcome was total IV morphine equivalent consumed in the first $24 \mathrm{~h}$. Secondary outcomes were postoperative pain scores (NRS) at rest and on movement, sedation scores recorded using a 5-point scale $(0=$ alert, $1=$ arouses to voice, $2=$ arouses with gentle tactile stimulation, $3=$ arouses with vigorous tactile stimulation, $4=$ lack of responsiveness) [14], the incidence of PONV using a 3-point scale $(0=$ none, $1=$ nausea, $2=$ vomiting), time to the first perception of pain ( $\mathrm{min}$ ), time to first void (h), adverse events (lightheadedness, tinnitus, perioral numbness, arrhythmia), quality of recovery based on QoR-40 questionnaire [15] at $24 \mathrm{~h}$ after surgery, patient satisfaction for postoperative pain relief using a five-point Likert scale at $24 \mathrm{~h}$ following surgery (1-highly satisfied, 2-satisfied, 3neutral, 4-not satisfied, 5-strongly dissatisfied) and the incidence of chronic post-surgical pain (CPSP) at 3 months.

Pain and sedation scores were assessed at PACU (on arrival, $15 \mathrm{~min}, 30 \mathrm{~min}, 1 \mathrm{~h}, 2 \mathrm{~h}$ ) and surgical unit (4h, 6 $\mathrm{h}, 8 \mathrm{~h}, 12 \mathrm{~h}, 24 \mathrm{~h}$ ). If the NRS score for pain was $>3$ at rest, morphine $1 \mathrm{mg}$ IV bolus was administered in the PACU, and repeated at $5 \mathrm{~min}$ interval until NRS was $\leq 3$. After $2 \mathrm{~h}$ of the stay in the PACU, the patients were transferred to the ward. In the surgical unit, tramadol $50 \mathrm{mg}$ IV was administered for NRS score $>3$ and $50 \mathrm{mg}$ was repeated at $10 \mathrm{~min}$ interval, up to a maximum dose of $300 \mathrm{mg}$ in the first $24 \mathrm{~h}$ for maintaining VAS score for pain $\leq 3$. The amount of tramadol consumed was converted to an equivalent dose of morphine from an online dose equivalent calculator (www.clincalc.com/Opioids). Ondansetron $4 \mathrm{mg}$ IV was administered for persistent nausea (lasting $>5 \mathrm{~min}$ ) or vomiting. CPSP was defined as pain that developed after a surgical procedure and persisted at least 3 months after surgery [16]. For this, the blinded investigator contacted the patients via telephone at 3 months after surgery. They were asked to answer the following question: Do you feel any pain in the operated area?

The sample size calculation was based on the study by $\mathrm{H}$ Kang on postoperative opioid consumption between the lidocaine infusion group and the placebo group in open inguinal hernia surgery [12]. Using an online statistical calculator (G power version 3.0.1), an estimated sample size of 29 patients in each study group achieved a power of $80 \%$ to detect a Cohen's d effect size of 0.76 in the primary outcome measure of opioid consumption, assuming a type I error of 0.05 . With an anticipated $10 \%$ drop-out, a total of 64 patients were enrolled.

The data were entered into excel software and analyzed using STATA version 13.0 (Stata Corporation, College Station, TX, USA). Histograms and the ShapiroWilk test was used to check the normality of the data. Normally distributed data were compared using a 2tailed t-test for independent samples. Non-normally distributed data were analyzed using the Mann-Whitney $\mathrm{U}$ test. For ordinal data, the Kruskal-Wallis test was applied. Chi-square test or Fischer's exact test was used for analyzing the categorical variables as appropriate. The finding with an associated $p$-value less than 0.05 was considered as statistically significant.

\section{Results}

Of the 82 screened patients, 18 patients were excluded (Fig. 1). Two patients in each group could not be traced during follow-up in 3 months. All outcomes were analyzed with the intention-to-treat principle. The demographics and surgical characteristics between the two groups did not reveal any significant differences (Table 1). The median (IQR) intraoperative fentanyl consumption was significantly less in the lidocaine group $0(0-0) \mu \mathrm{g}$ vs. $20(0-30) \mu \mathrm{g}$ in the saline group $(p<$ $0.001)$.

The cumulative median IV morphine equivalent consumption at $24 \mathrm{~h}$ postoperatively was significantly reduced in the lidocaine group than in the saline group (Fig. 2). The median morphine requirement in PACU was $0(0-1) \mathrm{mg}$ in the lidocaine group compared with 2 $(0-4) \mathrm{mg}$ in the saline group $(p=0.003)$. In the surgical unit, patients consumed a lesser median (IQR) tramadol in the lidocaine group, $0(0-0) \mathrm{mg}$ compared with the saline group $0(0-50) \mathrm{mg}(p<0.001)$. The median NRS scores at rest and during movement were significantly lower in the lidocaine group than in the saline group at all time points after surgery (Figs. 3 \& 4). The time to the first perception of pain was longer in those receiving lidocaine (median $30 \mathrm{~min}$ (15-30) compared with those receiving NS (median 10 min $(0-15) ; p<0.001)$.

A significant number of patients in the saline group had PONV and needed antiemetic compared to the lidocaine group (Table 2). Postoperative sedation scores 


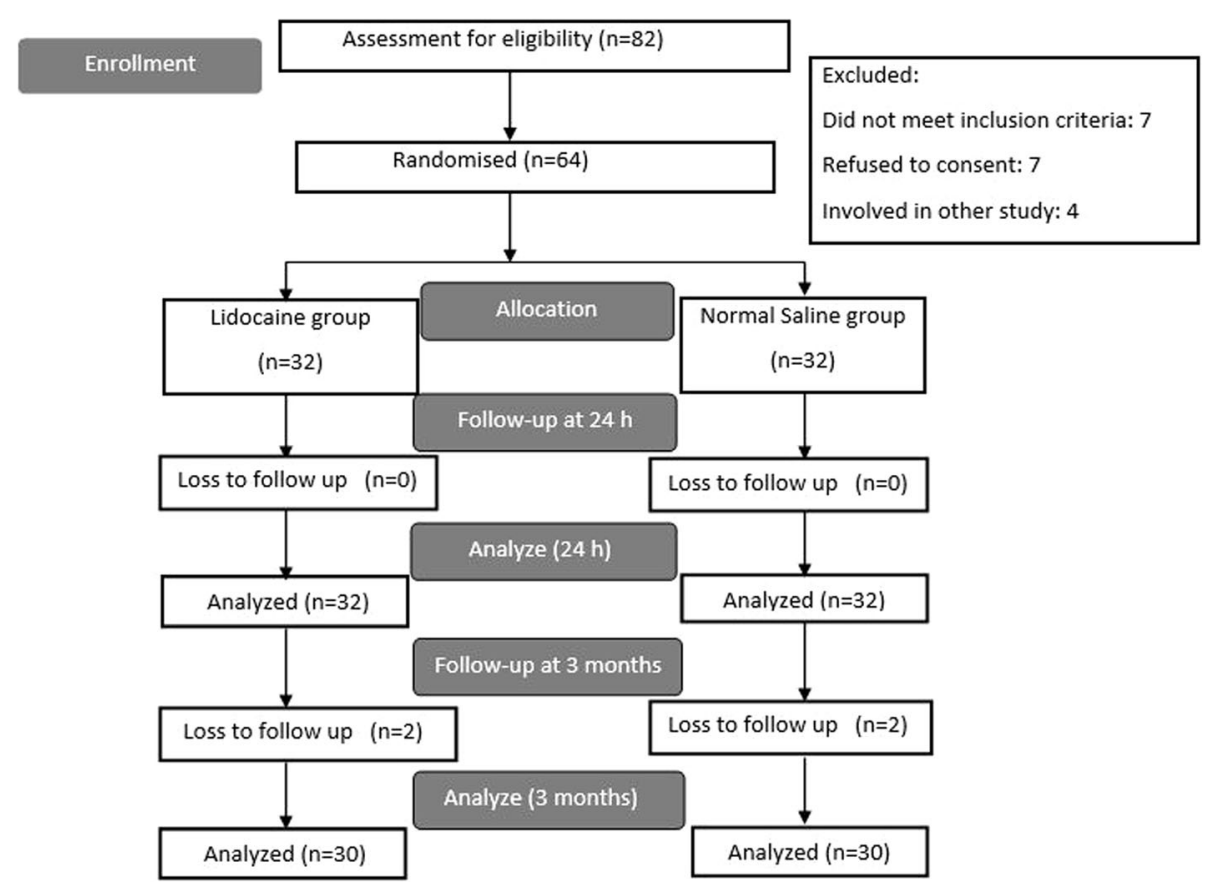

Fig. 1 CONSORT diagram of patient recruitment

were comparable between the two groups. Postoperative quality of recovery and patient satisfaction with postoperative pain relief was better in those receiving lidocaine (Table 2). No sign/symptoms related to lidocaine toxicity were observed. One patient in the lidocaine group developed intraoperative hypotension and bradycardia which was managed with ephedrine $5 \mathrm{mg}$ and atropine $0.4 \mathrm{mg}$ intravenously. When assessed in 3 months after surgery, two (7\%) patients in the lidocaine group developed CPSP compared to four $(13 \%)$ in the placebo group $(p=0.67)$.

\section{Discussion}

Our study showed that intraoperative infusion of low dose lidocaine decreased postoperative opioid requirement and pain intensity in comparison with normal saline in patients undergoing laparoscopic TEP inguinal hernia surgery. Patients receiving lidocaine had fewer occurrences of PONV, a better quality of recovery and were more satisfied with postoperative pain relief than those receiving saline. $\mathrm{Pa}$ tients complained of pain later in the lidocaine group than the saline group. No significant difference was observed for postoperative sedation and the incidence of chronic pain in 3 months.

It is well-established that lidocaine acts on voltagegated sodium channels when administered locally for peripheral nerve block. However, at lower concentration systemic lidocaine is insufficient to produce direct analgesia solely by blocking the neuronal sodium channels [17]. Although it is not fully understood how intravenous lidocaine produces analgesia, several potential

Table 1 Patient characteristics and surgical profiles of patients

\begin{tabular}{llll}
\hline Variables & $\begin{array}{l}\text { Lidocaine group } \\
(n=32)\end{array}$ & $\begin{array}{l}\text { Normal saline group } \\
(n=32)\end{array}$ & $\begin{array}{c}\text {-value } \\
\text { Age (years) }\end{array}$ \\
ASA PS $(1 / 2)$ & $40(30-52)$ & $43(33-52)$ & 0.61 \\
BMI $\left(\mathrm{kg} / \mathrm{m}^{2}\right)$ & $28 / 4$ & $27 / 5$ & 0.71 \\
Surgical site: Unilateral/Bilateral & $23.02 \pm 2.85$ & $22.01 \pm 2.02$ & 0.10 \\
Mesh fixation (Yes/No) & $25 / 7$ & $23 / 9$ & 0.56 \\
Duration of surgery $(\mathrm{min})$ & $31 / 1$ & $32 / 0$ & 0.50 \\
Intraoperative fentanyl supplement $(\mu \mathrm{g})$ & $60(48-90)$ & $75(60-90)$ & 0.49 \\
\hline
\end{tabular}

Notes: Values are median (IQR), mean (SD), number.

Abbreviations: BMI body mass index; ASA PS American society of Anesthesiologist physical status 


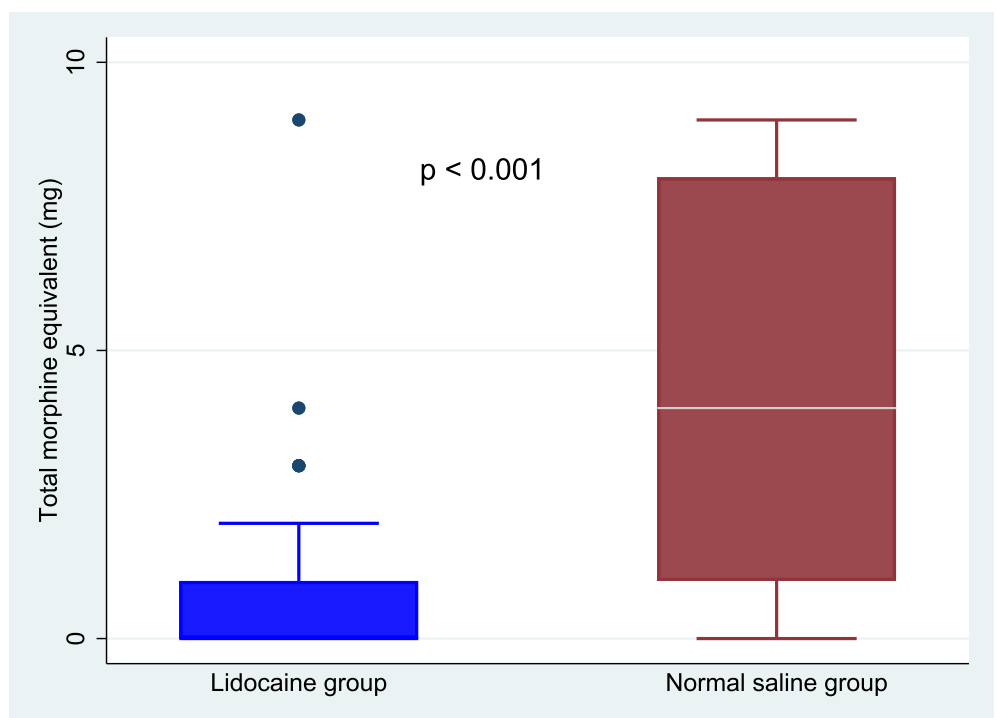

Fig. 2 Total morphine equivalent for $24 \mathrm{~h}$ postoperatively in patients receiving lidocaine and saline. Data are presented as median and interquartile range

mechanisms have been elucidated. Intravenous lidocaine increases acetylcholine concentration at the spinal level through an activation of both muscarinic and nicotinic receptors, and thereby prolongs the pain threshold [18]. Also, by activating central glycine (an inhibitory neurotransmitter) receptor, systemic lidocaine inhibits glutamate-induced excitatory response on the wide dynamic response in the spinal neurons [19]. The anti-hyperalgesic effect of IV lidocaine is due to blockade of NMDA receptor signaling and it is mediated indirectly by inhibition of the protein kinase $C$ pathway [20]. In addition to this, systemic lidocaine has anti-inflammatory properties as a decline in pro-inflammatory cytokines is observed in patients receiving lidocaine infusion [21-23]. Because perioperative pain is linked to an inflammatory process, modulation of this phenomenon with the administration of systemic lidocaine could significantly reduce

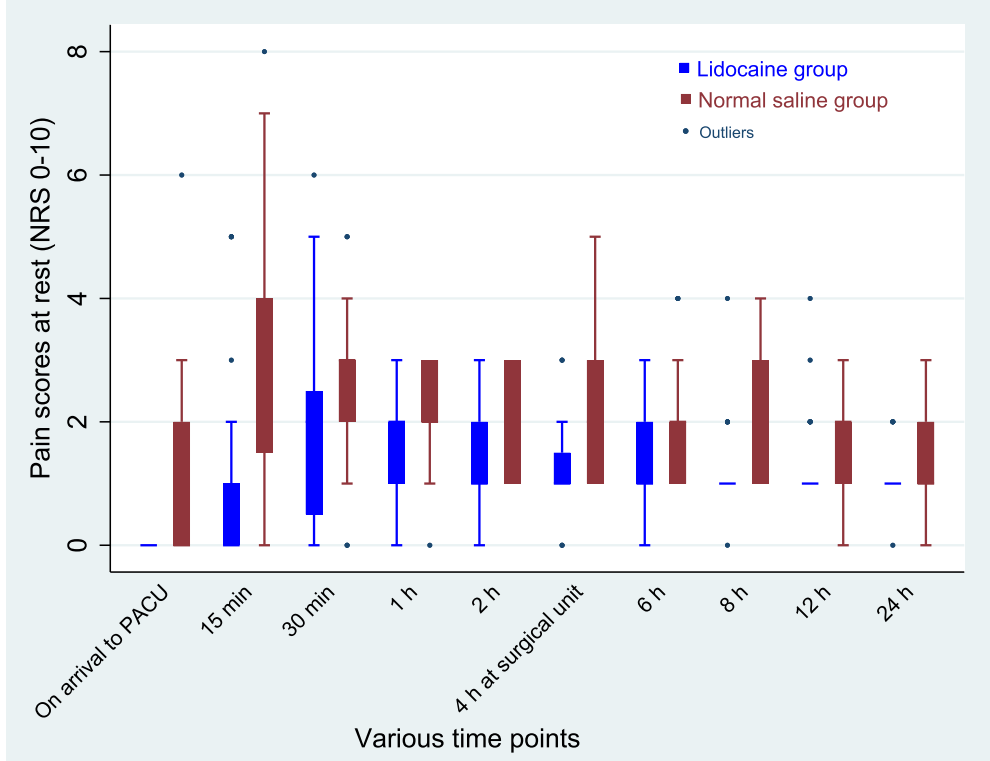

Fig. 3 Postoperative numerical rating pain (NRS) scores at various time points at rest. Data are median with error bars showing interquartile range. Significant difference between the groups was detected at all-time points $(p<0.05)$ 


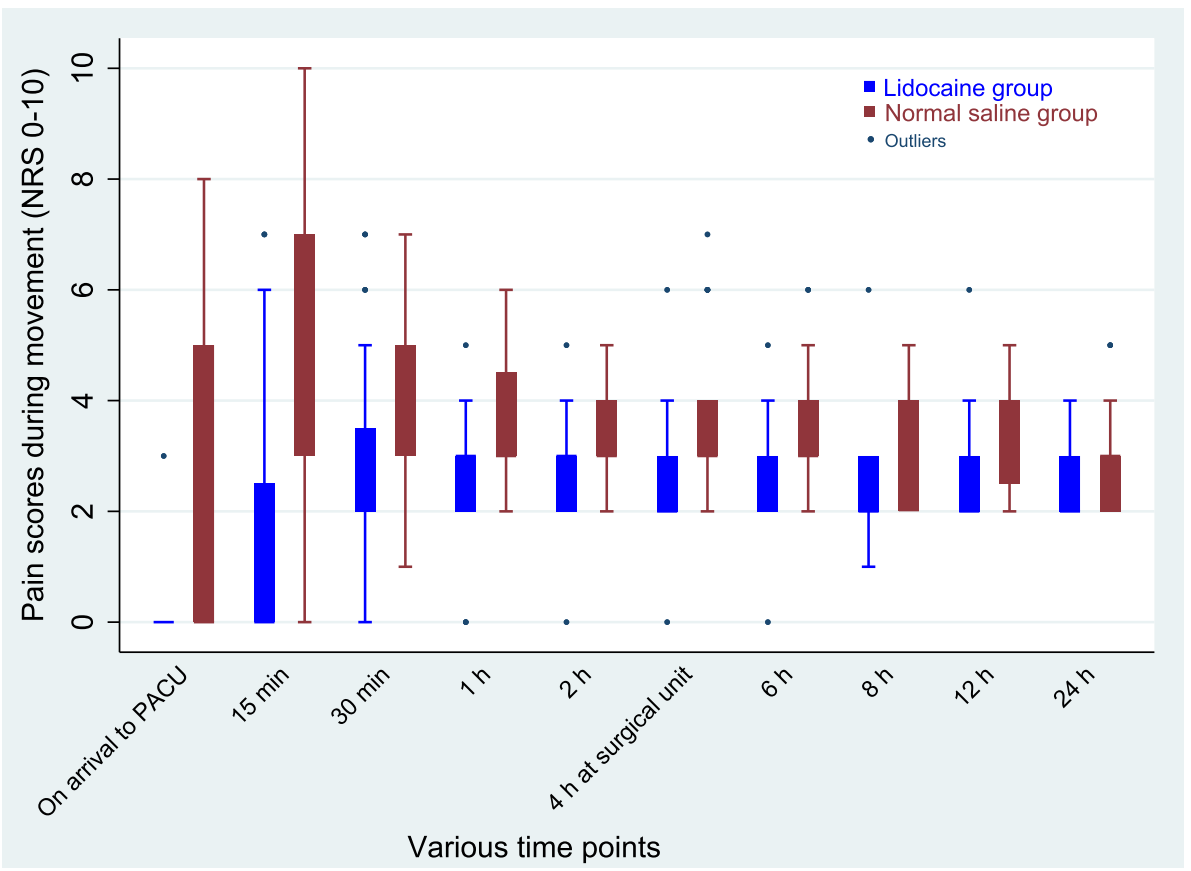

Fig. 4 Post-operative numerical rating pain scores (NRS) at various time points during movement. Data are median with error bars showing interquartile range. Significant difference between the groups was detected at all-time points $(p<0.05)$

pain. Another relevant question is to explain how the intraoperative administration of IV lidocaine does reduces opioid and pain scores beyond its infusion period. This could be due to its action on various receptors and signal cascades that produces an antinociceptive, anti-hyperalgesia and anti-inflammatory effects [8].

Because of its influence in several pain pathways, systemic lidocaine is widely investigated adjuvant in the regimen of multimodal analgesia to reduce postoperative opioid consumption and pain. Although the majority of studies have demonstrated the analgesic effect of lidocaine, several other trials failed to confirm it. A recently updated Cochrane review in 2018 has provided a muchneeded insight on the analgesic property of systemic lidocaine [9]. Random-effects meta-analysis from the same review on overall total postoperative opioid consumption favored lidocaine compared to the placebo (standardized mean difference (SMD) - 4.52 (mg, morphine equivalents (MEQ), $95 \% \mathrm{CI}-6.25$ to $-2.79, p<$ $0.001 ; \mathrm{I}^{2}=73 \% ; 40$ studies, 2201 participants). The results of our study also indicated a similar reduction in total postoperative opioid consumption in the first $24 \mathrm{~h}$ after surgery in the lidocaine group compared to the saline group (median difference of $-4 \mathrm{mg}$ morphine equivalents), despite using multimodal analgesia in both the groups.

Further, the aforementioned meta-analysis [9] demonstrated reduced pain scores at rest ("early time points"in the PACU or 1 to $4 \mathrm{~h}$ postoperatively) in the lidocaine

Table 2 Postoperative outcomes

\begin{tabular}{llll}
\hline & $\begin{array}{l}\text { Lidocaine group } \\
(n=32)\end{array}$ & $\begin{array}{l}\text { Saline group } \\
(n=32)\end{array}$ & $p$-value \\
\hline Nausea & $5(16 \%)$ & $14(44 \%)$ & 0.01 \\
Vomiting & $2(6 \%)$ & $8(25 \%)$ & 0.04 \\
Antiemetic needed & $3(9 \%)$ & $11(34 \%)$ & 0.01 \\
Time to first void; $h$ & $3(2-4)$ & $3(3-4)$ & 0.18 \\
Quality of recovery;QoR-40 scores & $194(194-196)$ & $184(183-186)$ & $<0.001$ \\
Patients with satisfaction scores $1 / 2 / 3 / 4 / 5^{\mathrm{a}}$ & $6 / 17 / 9 / 0 / 0$ & $2 / 13 / 17 / 0 / 0$ & 0.02 \\
\hline
\end{tabular}

Notes: Values are number (proportion), or median (IQR)

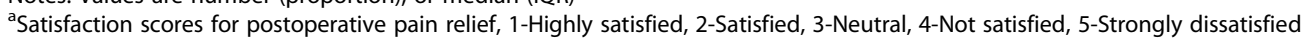


group compared to the control group (SMD - 0.50, 95\% CI -0.72 to- 0.28 ; Test for overall effect: $Z=4.41(P<$ $0.0001)$. This was equivalent to an average pain reduction between $0.37 \mathrm{~cm}$ and $2.48 \mathrm{~cm}$ on a VAS 0 to $10 \mathrm{~cm}$ scale in the lidocaine group. Likewise, at intermediate time points ( $24 \mathrm{~h}$ postoperatively) the standardized mean pain score at rest in the lidocaine group was 0.14 lower (95\% CI -0.25 to -0.04 ; Test for overall effect: $Z=2.63$ $(P=0.0086)$. This was equivalent to an average pain reduction in the lidocaine group between $0.48 \mathrm{~cm}$ and $0.10 \mathrm{~cm}$ on a VAS 0 to $10 \mathrm{~cm}$ scale. These results showed that lidocaine exerted a clinical difference of at least $1 \mathrm{~cm}$ on a $0-10$ VAS scores for pain at rest during early time points ( 1 to $4 \mathrm{~h}$ ); however, this difference was not observed at intermediate $(24 \mathrm{~h})$ time points. We too observed statistically significant difference in pain scores up to $24 \mathrm{~h}$ postoperatively, while the clinical difference of approximately $1 \mathrm{~cm}$ in NRS scores at rest was observed only up to $1 \mathrm{~h}$.

Due to substantial heterogeneity between studies, the authors of the same meta-analysis performed a sub-group analysis based on type of surgery, duration and dose of lidocaine infusions [9]. In the older version (Cochrane review, 2015) there was a clear beneficial effect in terms of pain reduction in laparoscopic abdominal surgery compared to open abdominal surgery [6]. However, in the current updated version, no significant difference was observed, although the trend was towards a beneficial effect for abdominal laparoscopic surgery [9].

The optimal dose and time to terminate lidocaine infusion are still an unsolved issue. We had limited the duration of lidocaine infusion until the patients trachea was extubated due to a lack of dedicated infusion pumps and monitoring at the surgical unit. One might hypothesize that longer infusions would lead to more lasting analgesia but studies are yet to confirm this. The current meta-analysis (2018) had categorized the studies according to the usage of low $\left(<2 \mathrm{mg} \cdot \mathrm{kg}^{-1} \cdot \mathrm{h}^{-1}\right)$ and high $\left(\geq 2 \mathrm{mg} \cdot \mathrm{kg}^{-1} \mathrm{~h}^{-1}\right)$ lidocaine doses in combination with either short (until the end of surgery or until PACU) or long ( $\geq 24 \mathrm{~h}$ postoperatively) duration of infusion [9]. However, they did not find any difference in outcomes when the dose or duration of the infusion was compared. A well designed randomized comparative study with a large sample size is needed to explore whether the continuation of systemic lidocaine infusion beyond the surgical period is effective.

In our study, fewer patients receiving lidocaine complained PONV compared to those receiving saline infusions. Similar to our finding, the Cochrane meta-analysis (2018) reported a significantly lower frequency of nausea in the lidocaine group than in the control group, but the vomiting rates did not differ [9]. Although, there is an association between lidocaine therapy and reduction in
PONV, it may not reflect a causal relationship. The most likely explanation for this association is related to lidocaine's opioid-sparing effects.

Recently, there is a growing interest in patientreported outcomes such as postoperative QoR and patient satisfaction. We observed better recovery profiles at $24 \mathrm{~h}$ of surgery in the lidocaine group as evident from the QoR scores. Similar to our study, De Oliveira and his colleagues reported greater QoR-40 scores at $24 \mathrm{~h}$ with perioperative lidocaine infusion for laparoscopic abdominal surgery $[24,25]$. Likewise, in our study patient satisfaction was better in lidocaine than saline group and no patient expressed dissatisfaction over the intervention. The current meta-analysis also supports this finding by revealing higher satisfaction scores in patients receiving lidocaine compared to placebo group (SMD $0.76,95 \%$ CI 0.46 to 1.06 ; $\mathrm{I}^{2}=0 \%$; 6 studies, 306 participants) [9]. Further, perioperative lidocaine infusion reduces the length of hospital stay as compared to the placebo. We considered this outcome as a limitation in our study because all our participants were required to stay in the hospital for $24 \mathrm{~h}$ after surgery. In terms of patient-reported outcomes, it would be interesting to explore the influence of perioperative lidocaine on the enhancement of recovery profiles, especially after major abdominal surgeries in future trials. A more recent meta-analysis focused on CPSP (total 6 trials included: 4 mastectomies, 1 thyroidectomy, 1 nephrectomy) found that systemic lidocaine administration reduces the development of CPSP [26]. As our study was not powered enough to detect the protective effect of lidocaine on CPSP after laparoscopic TEP, we would not like to draw any conclusion. This could be explored in a larger, multi-centric trial with CPSP as a primary outcome.

\section{Conclusions}

In summary, intraoperative lidocaine infusion decreases overall opioid requirement and postoperative pain intensity in patients undergoing laparoscopic TEP inguinal hernioplasty. It also lowers the incidence of PONV, improves the quality of recovery and patients satisfaction without any sedative effect.

\section{Abbreviations \\ TEP: Totally extraperitoneal; PONV: Postoperative nausea and vomiting; QoR: Quality of recovery; IQR: Interquartile range; IV: Intravenous; BPKIHS: BP Koirala Institute of Health Sciences; ASA: American Society of Anesthesiologists; NS: Normal Saline; NRS: Numerical rating scale; ETCO $\mathrm{CO}_{2}$ : End- tidal carbondioxide concentration; MAP: Mean arterial pressure; PACU: Post anesthesia care unit; CPSP: Chronic post-surgical pain; SMD: Standardized mean difference; MEQ: Morphine equivalent; VAS: Visual analogue scale}

\section{Acknowledgements}

Not applicable.

Authors' contributions

AG: This author helped in study design, patient recruitment, data collection and writing up of the first draft of the paper. AS: This author helped in study 
design, patient recruitment, data collection, analysis and interpretation of data, manuscript revision and final draft. BB: This author helped in study design, manuscript revision and final approval. BPS: This author helped in study design, manuscript first draft and final draft. All authors have read and approved the manuscript in its current state.

\section{Funding}

None.

\section{Availability of data and materials}

The datasets used and/or analysed during the current study are available from the corresponding author on reasonable request.

\section{Ethics approval and consent to participate}

The study was approved by the Institutional Review Committee (IRC), BP Koirala Institute of Health Sciences; reference number: IRC/520/015. Written informed consent was obtained from patients.

\section{Consent for publication}

Not applicable.

\section{Competing interests}

The authors declare that they have no competing interests.

\section{Author details}

${ }^{1}$ Department of Anesthesiology, Nepal Mediciti Hospital, Lalitpur, Nepal. ${ }^{2}$ Department of Anesthesiology \& Critical Care Medicine, BP Koirala Institute of Health Sciences, Dharan, Nepal.

Received: 30 January 2020 Accepted: 25 May 2020

Published online: 03 June 2020

\section{References}

1. Gan TJ, Joshi GP, Zhao SZ, Hanna DB, Cheung RY, Chen C. Presurgical intravenous parecoxib sodium and follow-up oral valdecoxib for pain management after laparoscopic cholecystectomy surgery reduces opioid requirements and opioid-related adverse effects. Acta Anaesthesiol Scand. 2004;48:1194-207.

2. Magheli A, Knoll N, Lein M, Hinz S, Kempkensteffen C, Gralla O. Impact of fast-track postoperative care on intestinal function, pain, and length of hospital stay after laparoscopic radical prostatectomy. J Endourol. 2011;25: 1143-7.

3. Lau CS, Chamberlain RS. Enhanced recovery after surgery programs improve patient outcomes and recovery: a meta-analysis. World J Surg. 2017:41:899-913.

4. Marret E, Rolin M, Beaussier M, Bonnet F. Meta-analysis of intravenous lidocaine and postoperative recovery after abdominal surgery. Br J Surg. 2008:95:1331-8

5. Sun Y, Li T, Wang N, Yun Y, Gan TJ. Perioperative systemic lidocaine for postoperative analgesia and recovery after abdominal surgery: a metaanalysis of randomized controlled trials. Dis Colon Rectum. 2012;55:1183-94.

6. Kranke $P$, Jokinen J, Pace NL, et al. Continuous intravenous perioperative lidocaine infusion for postoperative pain and recovery. Cochrane Database Syst Rev. 2015;7:CD009642.

7. Bajracharya JL, Subedi A, Pokharel K, Bhattarai B. The effect of intraoperative lidocaine versus esmolol infusion on postoperative analgesia in laparoscopic cholecystectomy: a randomized clinical trial. BMC Anesthesiol. 2019;19:198.

8. Dunn LK, Durieux ME. Perioperative use of intravenous lidocaine. Anesthesiology. 2017;126:729-37.

9. Weibel S, Jelting Y, Pace NL, et al. Continuous intravenous perioperative lidocaine infusion for postoperative pain and recovery in adults. Cochrane Database Syst Rev. 2018;6:CD009642.

10. Zhao JB, Li YL, Wang YM, Teng JL, Xia DY, Zhao JS, Li FL. Intravenous lidocaine infusion for pain control after laparoscopic cholecystectomy: a meta-analysis of randomized controlled trials. Medicine (Baltimore). 2018;97:e9771.

11. Li J, Wang G, Xu W, Ding M, Yu W. Efficacy of intravenous lidocaine on pain relief in patients undergoing laparoscopic cholecystectomy: a meta-analysis from randomized controlled trials. Int J Surg. 2018;50:137-45.
12. Kang $H$, Kim BG. Intravenous lidocaine for effective pain relief after inguinal herniorrhaphy: a prospective, randomized, double-blind, placebo-controlled study. J Int Med Res. 2011;39:435-45.

13. Liem MSL, van Steensel CJ, Boelhouwer RU, et al. The learning curve for totally extraperitoneal laparoscopic inguinal hernia repair. Am J Surg. 1996; 171:281-5.

14. De Witte JL, Alegret C, Sessler DI, Cammu G. Preoperative alprazolam reduces anxiety in ambulatory surgery patients: a comparison with oral midazolam. Anesth Analg. 2002;95:1601-6.

15. Myles PS, Weitkamp B, Jones K, Melick J, Hensen S. Validity and reliability of a postoperative quality of recovery score: the QoR-40. Br J Anaesth. 2000;84: $11-5$.

16. Treede RD, Rief W, Barke A, Aziz Q, Bennett MI, Benoliel R, Cohen M, Evers S, Finnerup NB, First MB, Giamberardino MA, Kaasa S, Kosek E, Lavand'homme P, Nicholas M, Perrot S, Scholz J, Schug S, Smith BH, Svensson P, Vlaeyen JW, Wang SJ. A classification of chronic pain for ICD-11. Pain. 2015;156: 1003-7.

17. Brinkrolf P, Hahnenkamp K. Systemic lidocaine in surgical procedures: effects beyond sodium channel blockade. Curr Opin Anaesthesiol. 2014;27:420-5.

18. Abelson KS, Höglund AU. Intravenously administered lidocaine in therapeutic doses increases the intraspinal release of acetylcholine in rats. Neurosci Lett. 2002:317:93-6.

19. Biella G, Sotgiu ML. Central effects of systemic lidocaine mediated by glycine spinal receptors: an iontophoretic study in the rat spinal cord. Brain Res. 1993;603:201-6.

20. Hahnenkamp K, Durieux ME, Hahnenkamp A, Schauerte SK, Hoenemann CW, Vegh V, Theilmeier G, Hollmann MW. Local anaesthetics inhibit signalling of human NMDA receptors recombinantly expressed in Xenopus laevis oocytes: role of protein kinase C. Br J Anaesth. 2006;96:77-87.

21. Yardeni IZ, Beilin B, Mayburd E, Levinson $Y$, Bessler $H$. The effect of perioperative intravenous lidocaine on postoperative pain and immune function. Anesth Analg. 2009;109:1464-9.

22. Kuo CP, Jao SW, Chen KM, Wong CS, Yeh CC, Sheen MJ, Wu CT. Comparison of the effects of thoracic epidural analgesia and i.v. infusion with lidocaine on cytokine response, postoperative pain and bowel function in patients undergoing colonic surgery. Br J Anaesth. 2006;97:6406.

23. Herroeder S, Pecher S, Schönherr ME, Kaulitz G, Hahnenkamp K, Friess H, Böttiger BW, Bauer H, Dijkgraaf MG, Durieux ME, Hollmann MW. Systemic lidocaine shortens length of hospital stay after colorectal surgery: a doubleblinded, randomized, placebo-controlled trial. Ann Surg. 2007;246:192-200.

24. De Oliveira GS Jr, Fitzgerald P, Streicher LF, Marcus RJ, McCarthy RJ. Systemic lidocaine to improve postoperative quality of recovery after ambulatory laparoscopic surgery. Anesth Analg. 2012;115:262-7.

25. De Oliveira GS Jr, Duncan K, Fitzgerald P, Nader A, Gould RW, McCarthy RJ. Systemic lidocaine to improve quality of recovery after laparoscopic bariatric surgery: a randomized double-blinded placebo-controlled trial. Obes Surg. 2014;24:212-8.

26. Bailey M, Corcoran $\mathrm{T}$, Schug $\mathrm{S}$, Toner A. Perioperative lidocaine infusions for the prevention of chronic postsurgical pain: a systematic review and metaanalysis of efficacy and safety. Pain. 2018;159:1696-704.

\section{Publisher's Note}

Springer Nature remains neutral with regard to jurisdictional claims in published maps and institutional affiliations.

Ready to submit your research? Choose BMC and benefit from:

- fast, convenient online submission

- thorough peer review by experienced researchers in your field

- rapid publication on acceptance

- support for research data, including large and complex data types

- gold Open Access which fosters wider collaboration and increased citations

- maximum visibility for your research: over $100 \mathrm{M}$ website views per year

At BMC, research is always in progress.

Learn more biomedcentral.com/submissions 